\title{
Rancang Bangun Pengisi Baterai Lead Acid Dan Li-Ion Secara Otomatis Menggunakan Mikrokontroler PIC 16F877A Bersumber Energi Matahari Dengan Pengendali PI
}

\author{
Bayu Setiaji $^{1}$, Wakhyu Dwiono ${ }^{2}$, Muhammad Taufiq Tamam ${ }^{3}$ \\ Program Studi S1 Teknik Elektro, Universitas Muhammadiyah Purwokerto \\ Fakultas Teknik dan Sains, Universitas Muhammadiyah Purwokerto
}

\section{Informasi Makalah}

Dikirim, 15 Agustus 2019

Direvisi, 19 Desember 2019

Diterima, 23 Desember 2019

\section{Kata Kunci: \\ Buck Converter \\ Lead Acid \\ Li-Ion \\ Mikrokontroler \\ Panel Surya}

\begin{abstract}
INTISARI
Baterai banyak digunakan dalam berbagai hal serta tersedia dalam bermacam jenis baterai. Salah satu jenis baterai yang dapat diisi ulang adalah baterai lead acid dan li-ion. Pada penelitian ini dilakukan rancang-bangun software dan hardware untuk mengatur pengisian baterai lead acid dan li-ion. Baterai lead acid yang digunakan berkapasitas $35 \mathrm{Ah} 12 \mathrm{~V}$ dan li-ion 3,4 Ah 3,7 V sebanyak tiga buah dirangkai seri. Sumber energi yang digunakan untuk mengisi baterai berasal dari panel surya. Untuk mengisi baterai lead acid digunakan dua buah panel surya $100 \mathrm{wp}$ sedangkan untuk mengisi baterai $l i-$ ion hanya digunakan satu panel surya $100 \mathrm{wp}$. Pengendali yang digunakan untuk pengisian baterai ini adalah mikrokontroler PIC16F877A. Untuk menjaga kestabilan arus selama pengisian baterai digunakan pengendali proporsional integral dengan besar nilai $\mathrm{Kp} 5$ dan $\mathrm{Ki}$ 1,5. Arus untuk mengisi baterai lead acid sebesar 3,6 A sedangkan arus untuk mengisi baterai li-ion sebesar $1 \mathrm{~A}$. Pengisian dihentikan secara otomatis jika tengan baterai telah mencapai level tertentu. Hasil pengujian menunjukan lama waktu mengisi baterai lead acid selama 10 jam dan li-ion 3 jam 20 menit.
\end{abstract}

\begin{abstract}
Batteries are widely used in various ways and are available in various types. The two famous type of rechargeable battery are lead-acid and Li-ion batteries. In this research, software and hardware design was carried out to regulate the charging of lead-acid and Li-ion batteries. Lead-acid batteries are used with a capacity of $35 \mathrm{Ah} 12 \mathrm{~V}$ and li Ahon $3.4 \mathrm{Ah} 3.7 \mathrm{~V}$ in three series. The energy source used to charge the battery comes from solar panels. To charge lead-acid batteries, two $100 \mathrm{wp}$ solar panels are used, while to charge li-ion batteries, only one $100 \mathrm{wp}$ solar panel is used. The controller used for charging this battery is a PIC16F877A microcontroller. To maintain the stability of the current during battery charging an integral proportional controller is used with a value of $\mathrm{Kp} 5$ and $\mathrm{Ki} \mathrm{1.5.} \mathrm{The} \mathrm{current} \mathrm{to} \mathrm{charge} \mathrm{the}$ lead-acid battery is 3,6 A while the current to charge the li-ion battery is $1 \mathrm{~A}$. Charging is stopped automatically if the battery level has reached a certain level. The test results show the lead-acid charging time is 10 hours and the liion is 3 hours 20 minutes.
\end{abstract}

\section{Korespondensi Penulis:}

Bayu Setiaji

Program Studi S1 Teknik Elektro

Universitas Muhammadiyah Purwokerto

J1 Raya Dukuhwaluh, Purwokerto, 53182

Email: bayusetiaji14@gmail.com

\section{PENDAHULUAN}

Baterai pada saat ini sudah menjadi bagian yang sangat penting dalam kehidupan sehari-hari. Penggunaan baterai juga sangat mudah ditemui, mulai dari kebutuhan rumah tangga hingga kebutuhan industri. Baterai berdasarkan sifatnya terdiri dari dua jenis yaitu baterai primer dan baterai sekunder. Baterai 
primer merupakan baterai yang habis dalam sekali pemakaian dan baterai sekunder merupakan baterai yang dapat diisi ulang karena reaksi kimia yang dimilikinya dapat dibalik[1].

Pengisian baterai dengan memanfaatkan energi matahari telah banyak dilakukan oleh para peneliti[2][3]. Menurut [2] agar dapat mengontrol pengisian baterai dengan baik, maka diperlukan sebuah charge controller yang dapat memantau level tegangan dan arus yang mengalir ke baterai. Apabila charge controller sudah mengetahui level tegangan baterai penuh maka pengisian akan terputus secara otomatis. Tujuannya adalah untuk melindungi baterai dari kerusakan akibat over charging.

Metode pengisian baterai telah banyak dikembangkan oleh para peneliti. Diantaranya adalah menggunakan ZCS[3], kemudian berbasis mikrokontroler PIC16F877A[4] serta menggunakan logika fuzzy [5][6]. Tegangan dan arus yang mengalir ke baterai dibaca melalui sensor efek Hall[7].

Berdasarkan masalah tersebut, maka dirancang alat pengisi baterai lead acid dan li-ion secara otomatis menggunakan mikrokontroler PIC 16F877A. Alat pengisi baterai lead acid dan li-ion diberikan sistem untuk dapat menghentikan proses pengisian baterai sehingga baterai lead acid dan li-ion tidak akan cepat rusak. Alat pengisi baterai lead acid dan li-ion ini dilengkapi dengan sensor tegangan, arus dan suhu untuk mengetahui kondisi baterai. Untuk memproses data hasil pengukuran menggunakan mikrokontroler PIC 16F877A dan hasil pengukurannya akan di tampilkan pada LCD 16x2.

\section{METODE PENELITIAN}

\subsection{Tahap Penelitian}

Untuk mewujudkan sistem monitoring parameter pada sistem pemanen energi matahari dengan model telemetri menggunakan komunikasi I2C (Inter Integrated Circuit) ini dilakukan tahapan-tahapan yang terdiri dari dilakukan yaitu, pada tahapan pertama pembuatan diagram alir sistem, pada tahapan yang kedua pembuatan perangkat keras, pada tahapan yang ketiga pembuatan perangkat lunak dan tahap yang terakhir analisis data.

Dalam melakukan kegiatan penelitian ini, ada beberapa tahapan yang perlu dilakukan supaya mendapatkan hasil yang diinginkan, dan tahapan-tahapan tersebut dapat dilihat pada Gambar 1 .

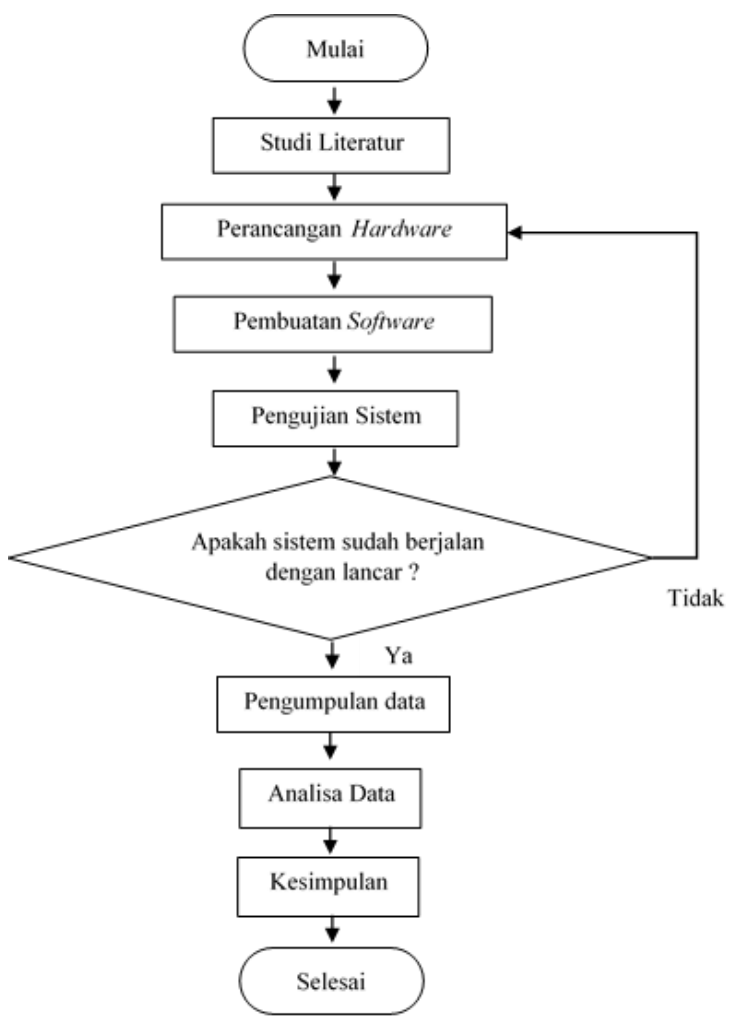

Gambar 1 Diagram Alir Penelitian 
Gambar 1 menjelaskan akan tahapan-tahapan atau metode yang dilakukan dalam penelitian ini. Dimulai dengan studi literatur, yaitu mencari sumber literatur yang mendukung dalam penelitian yang dilakukan seperti jurnal, buku, ataupun referensi rangkaian. Kemudian perancangan sistem alat, baik itu perancangan hardware maupun software. Selanjutnya dilakukan pengujian sistem, yang mana nantinya hasil data pengujian akan dianalisis datanya yang mana nantinya akan didapatkan kesimpulan dari penelitian yang dilakukan.

\subsection{Diagram Blok Sistem}

Sistem dalam penelitian ini terdiri dari tiga bagian yaitu input, kontrol dan output. Gambar diagram blok sistem dapat dilihat pada Gambar 2.

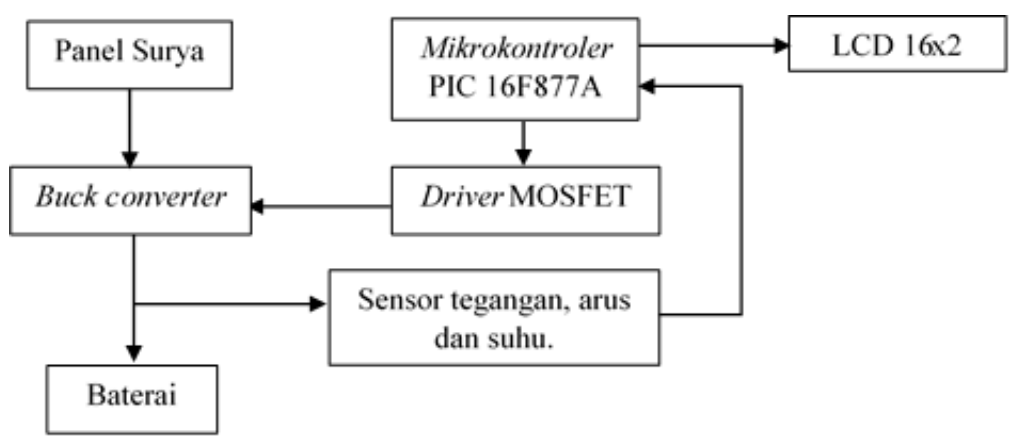

Gambar 2 Diagram Blok Sistem

\subsection{Diagram Alir Sistem}

Flow chart berfungsi untuk menggambarkan urutan proses secara mendetail meliputi hubungan antara suatu proses dengan proses lainnya dalam suatu program. Gambar flow chart pengisi baterai diperlihatkan pada Gambar 3.

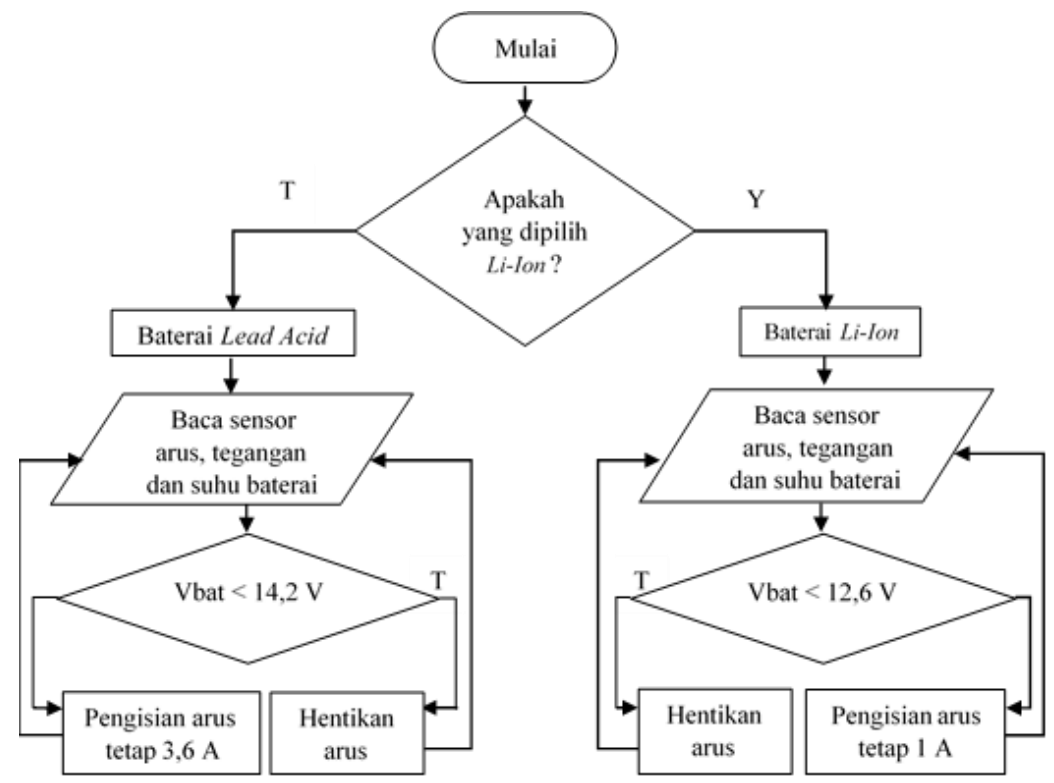

Gambar 3 Flowchart Pengisi Baterai 


\section{HASIL DAN PEMBAHASAN}

\subsection{Tahap Pengujian}

Jenis baterai yang digunakan dalam penelitian ini yaitu baterai lead acid dan li-ion. Baterai lead acid yang digunakan mempunyai kapasitas $35 \mathrm{Ah} 12 \mathrm{~V}$ yang dari perancangan baterai ini di charge dengan arus sebesar 3,6 A sehingga waktu yang dibutuhkan agar baterai penuh selama 9,7 jam atau 9 jam 43 menit, sumber listrik yang digunakan berasal dari panel surya. Sedangkan baterai li-ion yang digunakan mempunyai kapasitas sebesar 3,4 Ah 3,7 V sebanyak 3 buah yang dirangkai secara seri sehingga tegangannya akan menjadi 11,1 V sedangkan arus 3,4 Ah karena dirangkai seri. Arus tetap saat pengisian baterai li-ion sebesar 1 A sehingga waktu yang diperlukan supaya baterai penuh selama 3 jam 24 menit. Mikrokontroler yang digunakan yaitu PIC 16F877A diprogram untuk mengolah data tegangan, arus dan suhu serta mengatur supaya arus tetap pada saat pengisian baterai. Kontrol yang digunakan untuk mengatur supaya arus tetap yaitu pengendali PI. Data tegangan, arus dan suhu baterai akan ditampilkan pada LCD 16x2. Rangkaian driver MOSFET menggunakan IC IR2110 sebagai pengaktif kerja MOSFET. MOSFET yang digunakan adalah tipe $\mathrm{N}$ yaitu IRF540N yang digunakan untuk men-switching pada rangkaian buck converter. Panel surya yang digunakan berkapasitas 100 wp sebagai sumber energi listrik yang mudah didapatkan. Pada saat mengisi baterai lead acid digunakan dua panel surya sedangkan pada saat mengisi baterai li-ion digunakan satu panel surya.

\subsection{Pengujian Rangkaian Sistem}

\subsubsection{Pengujian Tampilan Menu LCD 16x2}

Pengujian LCD 16x2 bertujuan untuk menampilkan menu pilihan jenis baterai yang akan dipilih dan juga menampilkan hasil dari pembacaan sensor tegangan, sensor arus ACS712, dan sensor suhu LM35. Pengujian tampilan diperlihatkan dalam Gambar 4 sampai Gambar 6.

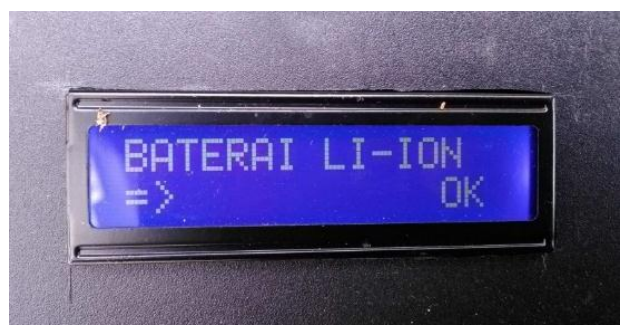

Gambar 4 Menampilkan Menu Jenis Baterai Li-Ion

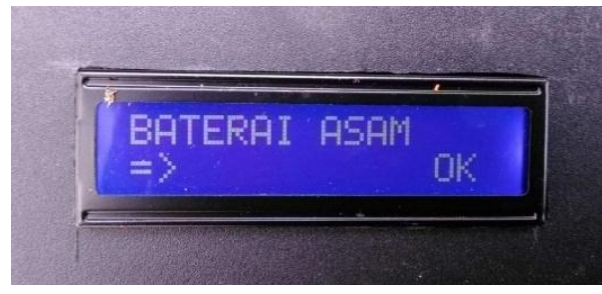

Gambar 5 Menampilkan Menu Jenis Baterai Lead Acid 


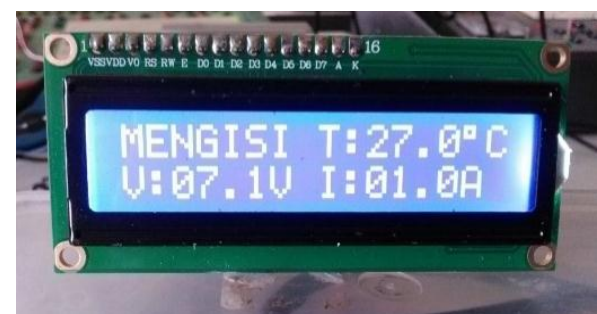

Gambar 6 Menampilkan Keadaan Tegangan, Arus dan Suhu

\subsubsection{Pengujian Sensor Tegangan}

Pengujian sensor tegangan bertujuan untuk mengetahui tegangan baterai pada saat pengisian yang ditampilkan pada LCD 16x2. Sensor tegangan ini dapat mendeteksi tegangan DC 0-100 V. Sensor tegangan ini disusun secara paralel terhadap beban yang mempunyai nilai resistor $19 \mathrm{~K}$ dan $1 \mathrm{~K}$, selanjutnya tegangan diambil pada titik tengah dari rangkaian tersebut dikirim ke mikrokontroler untuk dikonversi menjadi ADC (Analog to Digital Converter) sehingga sensor dapat membaca nilai tegangan tersebut.

Tabel 1 Pengujian Sensor Tegangan

\begin{tabular}{ccccc}
\hline \multirow{2}{*}{ No } & Power Supply(V) & Multimeter Digital (V) & Sensor Tegangan LCD (V) & Error \% \\
\hline 1 & 0 & 0 & 0 & 0 \\
2 & 2 & 2 & 2,2 & 10 \\
3 & 4 & 4 & 4,2 & 0,05 \\
4 & 6 & 6 & 6,2 & 3,3 \\
5 & 8 & 8 & 8,2 & 2,5 \\
6 & 10 & 10 & 10,2 & 2 \\
\hline \multicolumn{5}{c}{ Jumah } \\
\hline
\end{tabular}

Hasil pengujiannya ditampilkan dalam Tabel 1, dari data in dapat dilihat bahwa sensor tegangan yang dibuat sudah cukup baik, karena error yang di dapat 2,98 \% sehingga dapat diterapkan dalam alat pengisi baterai lead acid dan li-ion.

\subsubsection{Pengujian Sensor Arus ACS712}

Pengujian sensor arus ACS712 30 A bertujuan untuk mengetahui arus keluaran dari buck converter yang kemudian dibaca oleh PIC 16F877A dan ditampilkan pada LCD 16x2. Sensor ACS712 dapat mendeteksi nilai arus negatif dan positif sebesar -30 A sampai 30 A. Pada pengujian ini sensor ACS712 akan dibandingkan dengan ampere meter analog. Tabel 2 berikut adalah hasil pengujian sensor arus ACS712.

Tabel 2 Pengujian Sensor Arus ACS712

\begin{tabular}{ccccc}
\hline No & Beban Lampu DC 12 V (Watt) & Ampere Meter (A) & Sensor ACS712 (A) & Error \% \\
\hline 1 & 0 & 0 & 0 & 0 \\
2 & 20 & 1 & 1 & 0 \\
3 & 30 & 2 & 1,9 & 5 \\
4 & 50 & 3 & 3 & 0 \\
5 & 80 & 4 & 3,9 & 2,5 \\
6 & 100 & 4,6 & 4,5 & 2,2 \\
\hline \multicolumn{4}{c}{ Jumlah } \\
\hline
\end{tabular}


Dari data pada Tabel 2 dapat dilihat bahwa sensor arus ACS712 yang dibuat sudah cukup baik karena error yang di dapat 1,6\% sehingga dapat diterapkan dalam alat pengisi baterai lead acid dan li-ion.

\subsubsection{Pengujian Beban Ikal Terbuka}

Pengujian ini menggunakan PWM yang tetap dengan beban yang diubah. Data tegangan, arus akan ditampilkan pada LCD 16x2 yang akan dibandingkan dengan multimeter digital dan ampere meter analog. Multimeter digital sebagai pembanding dari sensor tegangan dan ampere meter sebagai pembanding dari sensor arus ACS712.

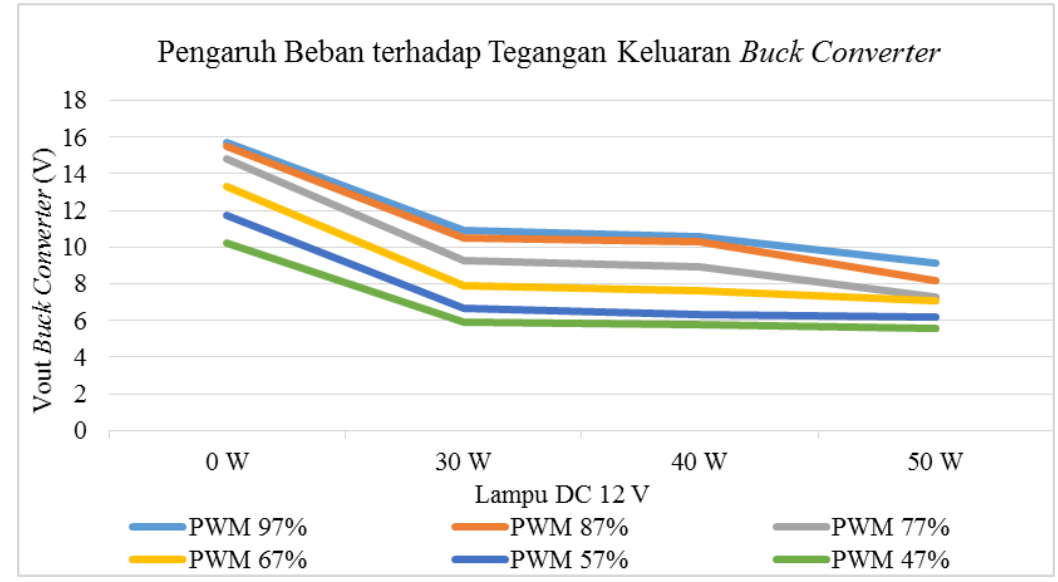

Gambar 3.4 Grafik Pengaruh Beban terhadap Tegangan Keluaran Buck Converter

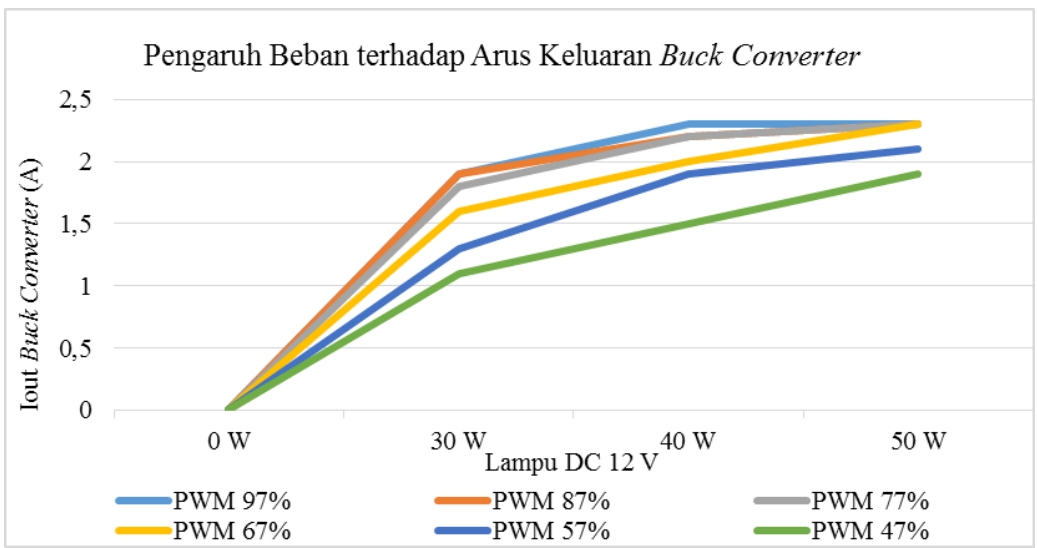

Gambar 7 Grafik Pengaruh Beban terhadap Arus Keluaran Buck Converter

\subsubsection{Pengujian Beban dengan Pengendali PI}

Pengendali PI dalam pengujian ini berfungsi untuk mengatur arus keluaran buck converter supaya tetap stabil meskipun beban diubah - ubah. Untuk nilai Kp dan Ki yang digunakan yaitu Kp 5 dan Ki 1,5.

Pada pengujian beban dengan pengendali PI terhadap tegangan diterapkan pengendali PI didalam mikrokontroler PIC 16F877A, tegangan keluaran buck converter (BC) akan berubah semakin kecil jika beban yang digunakan semakin besar sedangkan pada vout sensor ACS712 nilainya tetap menandakan bahwa keluaran arus buck converter (BC) tetap.

Hasil pengujian beban dengan pengendai PI terhadap arus dengan beban yang berubah-ubah sistem yang telah dibuat dapat bekerja dengan baik yang dapat mengatur supaya arus keluaran buck converter tidak berubah-ubah walaupun bebannya diubah. Nilai dari PWMlah yang akan berubah untuk menyesuaikan agar sesuai dengan setpoint arus. 


\subsubsection{Pengujian Pengisian Baterai Lead Acid}

Pengujian mengisi baterai lead acid menggunakan panel surya sebagai sumber energi listrik yang akan disimpan dalam baterai lead acid. Arus yang mengalir diatur menggunakan mikrokontroler PIC 16F877A yang telah diprogram dengan pengendali PI yang mengatur supaya arus yang mengalir tidak berubah-ubah atau arus konstan. Untuk nilai $\mathrm{Kp}$ dan $\mathrm{Ki}$ yang digunakan yaitu $\mathrm{Kp} 5$ dan $\mathrm{Ki}$ 1,5 Arus yang diatur dengan pengendali PI yaitu sebesar 3,6 A. Baterai yang digunakan berkapasitas 35 Ah $12 \mathrm{~V}$ sehingga waktu yang dibutuhkan agar baterai penuh sebesar 9,7 jam atau 9 jam 43 menit. Pada pengujian ini tegangan baterai akan semakin bertambah dan arus pengisian tetap tidak turun, jika tanpa pengendali PI maka arus yang mengalir akan turun seiring dengan bertambahnya tegangan baterai dan kemudian tidak dapat mengisi baterai. Pengisian akan berhenti secara otomatis jika terdeteksi tegangan baterai sebesar 14,2 V yang menandakan bahwa baterai lead acid sudah penuh. Faktor cuaca juga berpengaruh dalam pengisian baterai, jika dalam keadaan mendung tidak dapat mengisi baterai dan jika semakin cerah sinar matahari maka pengisian dapat dilakukan.

\subsubsection{Pengujian Pengisian Baterai $\mathrm{Li}-\mathrm{Ion}$}

Pengujian mengisi baterai li-ion sama seperti mengisi baterai lead acid menggunakan panel surya sebagai sumber energi listrik yang akan disimpan dalam baterai berjenis $l i$-ion. Arus yang mengalir diatur menggunakan mikrokontroler PIC16F877A yang telah diprogram dengan pengendali PI untuk mengatur supaya arus yang mengalir tidak berubah-ubah atau arus konstan. Untuk nilai Kp dan Ki yang digunakan yaitu Kp 5 dan Ki 1,5 Arus yang diatur dengan pengendali PI yaitu sebesar 1 A. Baterai yang digunakan berkapasitas 3,4 Ah 3,7 V sehingga waktu yang dibutuhkan agar baterai penuh sebesar 3 jam 24 menit dari keadaan baterai kosong. Pengisian akan berhenti secara otomatis jika terdeteksi tegangan baterai sebesar 12,6 $\mathrm{V}$ yang menandakan bahwa baterai li-ion sudah penuh. Faktor cuaca juga berpengaruh dalam pengisian baterai $l i$-ion, jika dalam keadaan mendung tidak dapat mengisi baterai dan jika semakin cerah sinar matahari maka pengisian dapat dilakukan.

\section{KESIMPULAN}

Sistem pengisi baterai lead acid dan li-ion secara otomatis menggunakan mikrokontroler PIC 16F877A yang bersumber energi matahari dengan pengendali PI sudah berjalan dengan baik. Pengendali PI dapat mengatur supaya arus pengisian baterai konstan.

\section{DAFTAR PUSTAKA}

[1] Siburian, Bukry Chamma dan Bahriun, T. Ahri. 2015. Perancangan Alat Pengisi Baterai Lead Acid Berbasis Mikrokontroler ATMEGA 8535. Sumatera Utara: DTE FT USU. Vol.13, No.35: 42

[2] Astra, I. M., dan Sidopekso, S. 2011. Studi Rancang Bangun Solar Charge Controller Dengan Indikator Arus, Tegangan Dan Suhu Berbasis Mikrokontroler Atmega 8535. Jurnal Fisika Dan Aplikasinya, Vol 11, No 1.

[3] Jamil, Irfan., Jinquan, Zhao., Jamil, Rehan., Jamil, Rizwan., Samee, Abdus. 2013. A battery charging system \& appended ZCS (PWM) resonant converter $d c-d c$ buck: technique for battery charger to yield efficient performance in charging shaping. Electrical and Electronics Engineering: An International Journal (ELELIJ) Vol 2, No 2.

[4] AbduAllah, Zaki Majeed., Mahmood, Omar Talal., AL-Naib, Ahmed M. T. Ibraheem. 2014. Photovoltaic Battery Charging System Based on PIC16F877A Microcontroller. International Journal of Engineering and Advanced Technology (IJEAT). Vol 3.

[5] Patil A. R., K. D, Atar., A. A, Potdar., R. R, Mudholkar. 2013. Embedded Fuzzy Module for Battery Charger Control. International Journal of Advanced Research in Electrical, Electronics and Instrumentation Engineering (IJAREEIE). Vol 2.

[6] Dwiono,Wakhyu dan Taufiq, Arif Johar. 2017. kinerja pengendali fuzzy untuk pengisian baterai menggunakan arus tetap. Purwokerto : Universitas Muhammadiyah

[7] Allegro MicroSystem. 2017. Data Sheet ACS712 Fully Integrated, Hall Effect-Based Linear Current Sensor with 2.1 kVRMS Voltage Isolation and a Low-Resistance Current Conductor. U.S.A. Rev 7. 